\title{
An Overview of Honey: Its Composition, Nutritional and Functional Properties
}

\author{
Engin Gündoğdu ${ }^{1}$, Songül Çakmakçı ${ }^{2}$ and İhsan Güngör Şat ${ }^{2}$ \\ 1. Department of Food Engineering, Gümüşhane University, Gümüşhane 29100, Turkey \\ 2. Department of Food Engineering, Atatürk University, Erzurum 25240, Turkey
}

\begin{abstract}
Honey is a natural food/product that can be used for various purposes. High-quality honey can be distinguished by flavor and consistency. The composition, appearance, sensory perception and biological effects of honey depend on the floral source used to collect nectar by honeybee, seasonal and climatic factors. Honey flavor is an important factor for the consumer's choice. About $95 \%$ of the honey dry matter is composed of carbohydrates. The main sugars are the monosaccharides fructose and glucose and 5-10\% of the total carbohydrates are oligosaccharides. Honey contains proteins, minerals, vitamins, polyphenols, vitamins, enzymes, organic acids and volatiles. The three main honey enzymes are diastase, invertase and glucoseoxidase. The average $\mathrm{pH}$ of honey is 3.9 , but can range from 3.4 to 6.1 . The viscosity of honey is affected by both temperature and water content. The glycemic index of honey varies from 32 to 87 . Honey has been shown to possess antioxidant, antimicrobial, antiviral, antiparasitory, anti-inflammatory, antimutagenic and anticancer effects. The low water activity of honey inhibits microbial growth. The antibacterial effect of honey, is mostly against gram-positive bacteria. Honey is a source of natural antioxidants, which are effective in reducing the risk of many diseases. Most of the health promoting properties of honey are only achieved by application of rather high doses of honey such as 50 to $80 \mathrm{~g}$ per intake. This information shows that honey has a wide range of positive effects on nutrition and health.
\end{abstract}

Key words: Honey, composition, nutrition, health, functional properties.

\section{Introduction}

Honey is a natural substance produced by honeybees (Apis mellifera) from the nectar of flowers which is a sweet, flavorful, viscose liquid. It has been used as a food and medical product since the earliest times [1]. It is well known for its nutritional and medicinal qualities resulting from healthy ingredients which are strongly associated with its floral origin [2, 3]. Also, it composition and quality vary depending on production method, climatic conditions of the region, conditions of handling and storage and the nectar, which is the source of honey [4]. This natural product is a concentrated aqueous solution of different carbohydrates such as fructose, glucose, maltose, sucrose, and other oligo- and polysaccharides [5]. Also It contains certain minor constituents including proteins, enzymes, amino and organic acids, lipids,

Corresponding author: Songül Çakmakçı, Prof. Dr., research fields: dairy science and technol, food chem. vitamins, minerals, flavor compounds and flavonoids and phenolic compounds [1, 3]. However, honey constituents can be changed during storage because of different chemical reactions such as fermentation, oxidation and thermal processing [6]. In this review, it is aimed to give summary information about general composition, quality criteria, nutritional and functional properties of honey.

\section{Composition of Honey}

The composition of honey basicly varies to the floral source, but seasonal, environmental factors and processing conditions are also important [1]. Honey is a source of simple carbohydrates of which fructose $(38.5 \%)$ and glucose (31\%) are of total $82.4 \%$ carbohydrate. The remaining $12.9 \%$ of carbohydrates consists of maltose, sucrose and other sugars [7]. Other sugars are isomaltose, nigerose, turanose, maltulose; kojibiose; alpha beta-trehalose, gentiobiose, 
laminaribiose; maltotriose, 1-kestose, panose, isomaltosyl glucose, erlose, isomaltosyltriose, theanderose, centose, isopanose, isomaltosyltetraose and isomalto sylpentaose. But not all these sugars exist in nectar but forms during ripening or the effect of other factors such as bee enzymes and acids [8]. The protein content of honey changes to the species of the honeybees. For example while protein varies from $0.1 \%$ to $3.3 \%$ in Apis cerana, it varies from $0.2 \%$ and $1.6 \%$ in Apis mellifera [9]. The portion of amino acids in honey is $1 \%$. Altough the most abundant amino acid is proline which constitues $50-85 \%$ there are 26 aminoa cids such as glutamic acid, aspartic acid, glutamine, histidine, glycine, threonine, $\beta$-alanine, arginine, $\alpha$-alanine, aminobutyric acid, proline, tyrosine, valine, methionine, cysteine, isoleucine, leucine, tryptophan, phenylalanine, ornithine, lysine, serine, asparagine and alanine [10]. Enzymes in honey are originated from two sources: invertase, glucose oxidase, and amylase comes from hypopharyngeal glands of worker honeybees. On the other hand, catalase, acid phosphatase and a small proportion of amylase are arised from plants [8]. The mineral and vitamin content of honey is very low, which constitues $0.02 \%$ of its weight [8]. While potassium constitues almost one third of the total mineral content of honey, it also contains sodium, iron, copper, silicon, manganese, calcium and magnesium at small quantitiy [11]. Organic acids which constitue $0.57 \%$ of honey give honey acidity. The predominant acid in honey is gluconic acid and citric acid, a good parameter for discrimination floral and honey drew [12]. On the other hand, free acidity which is important for honey deterioration is resulted from some inorganic acids [13]. The major transformations associated with storage are free acidity, lactic acidity, diastase activity and 5-hydroxymethylfurfural (HMF) content [13].

\section{Quality Characteristic of Honey}

The quality of honey is mainly associated by its sensorial, chemical, physical and microbiological characteristics. The European Council Directive 2001/110/EC [14] defines honey and establishes minimum quality standards for honey when placed on the market as honey or used as an ingredient in products intended for human consumption. In 2015 the European Commission organised an "EU coordinated control plan" to assess the prevalence on the market of honey adulterated with sugars and honeys mislabelled with regard to their botanical source or geographical origin [15]. The major criteria of characteristics of honey are moisture content, electrical conductivity, ash content, reducing and non-reducing sugars, free acidity, diastase activity and HMF content [16]. For this reason, various countries set strict standards for commercial honey, including specific physical properties and chemical compositions. Thermal treatment which is applied for delaying its crystallisation, and destroying the contaminate microorganisms may destroy vitamins and bionutrients, and produce a simultaneous decrease in diastase activity and an increase in HMF content. For controlling of diastase activity and HMF content, national and international parameters are used to limit thermal treatment application [17].

\section{Sensory, Physical and Chemical Properties of Honey}

Sensory property such as color and flavor is a major parameter in determining the quality of honey and changes to the several factors such as the geographical, and seasonal conditions and as the floral source [18]. The most changeable feature of honey is color and has great importance as it is an indicator of its origin and quality [19]. The color of honey varies from very pale yellow through amber and dark reddish amber to nearly black [20]. The mass-produced honey, which is a mixture of many honey, can be uniformly colored. The individual harvested honey may have a range of colors depending on the season of the nectar (flower origin), the time between nectar collection and honey harvesting, production details such as heating, 
temperature and/or storage time and pollen grains and morphology [21, 22]. On the other hand mineral content has effect on the color and the taste of honeys and the higher content of minerals make the color darker and stronger taste [23]. Another aspect of honey quality is its appearance. It can be fluid, viscous, partly or totally crystallized form and appearance is important for commercial honey, as consumers demand a fluid, non-crystallized product. Altough raw honey is in a liquid state, it can contain small or big crystalls dending on numerous factors such as origin, temperature, moisture content, and sugar content [24]. The $\mathrm{pH}$ of honey ranges from 3.2 to 4.5 [8]. The water activity of honey, which is important on the spoilage of honey, is within a range of 0.5-0.65 [25]. Honey flavor is related with the volatile compounds and they can vary to the seasonal conditions and geographical origin [26]. On the other hand aroma of honey depends also on the quantity and type of acids and amino acids [27]. The another property of honey is viscosity, which is considered one of the most important properties of honey. This property is important especially for beekeepers and honey processors, because the rheological behavior has importance for a longer shelf life and facilitating proper handling, packing, and processing of honey [28].

\section{Nutritional, Antimicrobial and Functional Properties of Honey}

Honey has a very long history of human consumption as the oldest sweetener and health food. As far back as $5500 \mathrm{BC}$, honey was mentioned in the writings of Egypt, India, and China [29]. Honey is food consumed worldwide and is increasingly being used as a substitute for granulated sugar. Altough honey is the most sweety food its glycemic load is low [30]. Honey has been widely used as food and medicine by all generations, traditions, and civilizations. Honey has been used by humans to treat a variety of ailments through topical application, but it recently gained importance as of the antiseptic and antimicrobial properties too. Honey has been reported to be effective in a number of human pathologies. Clinical studies have demonstrated that application of honey to severely infected cutaneous wounds rapidly clears infection from the wound and improves tissue healing. Studies showed that honey has a broad-spectrum antimicrobial (antibacterial, antifungal, antiviral, and antimycobacterial) properties of honey. It may be attributed to the acidity (low $\mathrm{pH}$ ), osmotic effect, high sugar concentration, presence of bacteriostatic and bactericidal factors which are hydrogen peroxide, antioxidants, lysozyme, polyphenols, phenolic acids, flavonoids, methylglyoxal, and bee peptides [29]. Honey is an ingredient for traditional medicine, because of its dietary and curative properties since ancient times [31]. Many studies demonstrated that honey is a source of natural antioxidants which are effective in reducing the risk of heart disease, cancer, immune-system decline, cataracts, different inflammatory processes etc. The components responsible for antioxidative effect of honey are flavonoids, phenolic acids, ascorbic acid, catalase, peroxidase, carotenoids and products of the Maillard reaction [32]. The quantity of these components varies widely according to the floral and geographical origin of honey [20]. Functional properties of honey inhuman health depend largely on the floral source of the honey and these properties could be related to honey high osmolarity and antibacterial properties [33]. As polyfloral honeys may contain higher levels of flavonoid and phenolic compounds than monofloral ones they have higher antioxidant activity. This for, honey consumption has potential health benefits due to the antioxidant and antimicrobial properties of honey [34]. Honey contains more than 200 components, with fructose, glucose, and water as main substances [35]. The antioxidant activity depends on the floral source, as well as on seasonal and environmental factors and the processing may also 
have effect on composition and antioxidant activity of honey [36].

\section{Consumption of Honey}

Honey, a natural sweet substance, has a wide range of applications in the food industry. It can be consumed directly or be used as an ingredient of various processed foods as it has nutritional value and unique flavor [37]. On the other hand, honey is often enriched with pollen, propolis, royal jelly, or other primary bee products to enhance its taste, nutritional and medicinal properties without changing its composition. Also, honey prepared with nuts such as walnut, almond and hazel-nut and dried fruits is consumed as a tasty dessert [38]. Altough honey is used as sweetening agent in foods, it is also used as a food preservative [39]. On the other hand, healthier lemonade is made using instead of sucrose.

\section{Conclusions}

High-quality honey has a variety of positive nutritional and health effects. The quality of honey depends on its floral origin and chemical composition. Honey has been always taken place in diet not only nutritional aspects but also for health properties. The main nutrition- and health-relevant components are the carbohydrates, which make it an excellent energy source, especially for children and sportsmen. Honey is highly special, nutritious, functional and healty food. Except nutritious value, it inhibits some food spoilage organisms too. As it has high antioxidant activity it is prefered as not only direct consuption but also supportive or preservative in foods. To make use of the miracles of honey, the tricks of honey should be avoided. Quality honey production and consumption should be increased. Adulteration of honey, decreases income of honest producers and it also has negative effects on consumers' nutrition and health.

\section{Conflict of Interest}

The authors have declared no conflict of interest.

\section{References}

[1] Alvarez-Suarez, J. M., Tulipani, S., Romandini, S., Bertoli, E., and Battino, M. 2010. "Contribution of Honey in Nutrition and Human Health: A Review." Mediterranean J. Nutr. Metab. 3: 15-23.

[2] Kaygusuz, H., Tezcan, F., Bedia Erim, F., Yildiz, O., Sahin, H., Can, Z., and Kolayli, S. 2016. "Characterization of Anatolian Honeys Based on Minerals, Bioactive Components and Principal Component Analysis." LWT-Food Sci. Technol. 68: 273-9.

[3] Arawwawala, L. D. A. M., and Hewageegana, H. G. S. P. 2017. "Health Benefits and Traditional Uses of Honey: A Review." J. Apither. 2: 9-14.

[4] Tosun, M. 2013. "Detection of Adulteration in Honey Samples Added Various Sugar Syrups with 13C/12259 C Isotope Ratio Analysis Method." Food Chem. 138: 1629-32.

[5] Escuredo, O., Míguez, M., Fernández-González, M., and Seijo, M. C. 2013. "Nutritional Value and Antioxidant Activity of Honeys Produced in a European Atlantic Area." Food Chem. 138: 851-6.

[6] Da Silva, P. M., Gauche, C., Gonzaga, L. V., Costa, A. C. O., and Fett, R. 2016. "Honey: Chemical Composition, Stability and Authenticity."Food Chem. 196: 309-23.

[7] Khan, F., Abadin, Z. U., and Rauf, N. 2007. "Honey: Nutritional and Medicinal Value." Int. J. Clin. Pract. 61: 1705-7.

[8] Jeffrey, A. E., and Echazarreta, C. M. 1996. "Medical Uses of Honey." Rev. Biomed. 7: 43-9.

[9] Won, S.-R., Lee, D.-C., Ko, S. H., Kim, J.-W., and Rhee, H.-I. 2008. "Honey Major Protein Characterization and Its Application to Adulteration Detection." Food Res. Int. 41: 952-6.

[10] Hermosin, I., Chicón, R. M., and Dolores Cabezudo, M. 2003. "Free Amino Acid Composition and Botanical Origin of Honey." Food Chem. 83: 263-8.

[11] Alqarni, A. S., Owayss, A. A., Mahmoud, A. A., and Hannan, M. A. 2014. "Mineral Content and Physical Properties of Local and Imported Honeys in Saudi Arabia." J. Saudi Chem. Soc. 18: 618-25.

[12] Karabagias, I. K., Badeka, A., Kontakos, S., Karabournioti, S., and Kontominas, M. G. 2014. "Characterisation and Classification of Greek Pine Honeys according to Their Geographical Origin Based on Volatiles, Physicochemical Parameters and Chemometrics." Food Chem. 146: 548-57.

[13] Moreira, R. F. A., De Maria, C. A. B., Pietroluongo, M., and Trugo, L. C. 2007. "Chemical Changes in the Non-volatile Fraction of Brazilian Honeys during Storage 
under Tropical Conditions." Food Chem. 104: 1236-41. [14] EU. 2001. The European Council Directive 2001/110/EC.

[15] EC. 2015. Honey (2015-17). JRC Technical Reports. Ref. Ares(2016)6932951-13/12/2016.

[16] Alvarez-Suarez, J. M., Tulipani, S., Díaz, D., Estevez, Y., Romandini, S., Giampieri, F., Damiani, E., Astolfi, P., Bompadre, S., and Battino, M. 2010. "Antioxidant and Antimicrobial Capacity of Several Monofloral Cuban Honeys and Their Correlation with Color, Polyphenol content and Other Chemical Compounds." Food Chem. Toxicol. 48: 2490-9.

[17] Tosi, E., Ciappini, M., Ré, E., and Lucero, H. 2002. "Honey Thermal Treatment Effects on Hydroxymethyl Furfural Content." Food Chem. 77: 71-4.

[18] Anupama, D., Bhat, K. K., and Sapna, V. K. 2003. "Sensory and Physico-chemical Properties of Commercial Samples of Honey." Food Res. Int. 36: 183-91.

[19] González-Miret, M. L., Ayala, F., Terrab, A., Echávarri, J. F., Negueruela, A. I., and Heredia, F. J. 2007. "Simplified Method for Calculating Colour of Honey by Application of the Characteristic Vector Method." Food Res Int. 40: 1080-6.

[20] Bertoncelj, J., Doberšek, U., Jamnik, M., and Golob, T. 2007. "Evaluation of the Phenolic Content, Antioxidant Activity and Colour of Slovenian Honey." Food Chem. 105: 822-8.

[21] Ball, D. W. 2007. "The Chemical Composition of Honey." J. Chem. Edu. 84: 1643.

[22] Terrab, A., González-Miret, L., and Heredia, F. J. 2004. "Colour Characterisation of Thyme and Avocado Honeys by Diffuse Reflectance Spectrophotometry and Spectroradiometry." Eur. Food Res. Technol. 218: 488-92.

[23] González-Miret, M. L., Terrab, A., Hernanz, D., Fernández-Recamales, M. Á., and Heredia, F. J. 2005. "Multivariate Correlation between Color and Mineral Composition of Honeys and by Their Botanical Origin." $J$. Agr. Food Chem. 53: 2574-80.

[24] Escriche, I., Visquert, M., Juan-Borrás, M., and Fito, P. 2009. "Influence of Simulated Industrial Thermal Treatments on the Volatile Fractions of Different Varieties of Honey." Food Chem. 112: 329-38.

[25] Gleiter, R. A., Horn, H., and Isengard, H. D. 2006. "Influence of Type and State of Crystallisation on the Water Activity of Honey." Food Chem. 96: 441-5.

[26] Silvano, M. F., Varela, M. S., Palacio, M. A., Ruffinengo, S., and Yamul, D. K. 2014. "Physicochemical Parameters and Sensory Properties of Honeys from Buenos Aires Region." Food Chem. 152: $500-7$.
[27] Bogdanov, S., Jurendic, T., Sieber, R., and Gallmann, P. 2008. "Honey for Nutrition and Health: A Review.” J. Am. Coll. Nutr. 27: 677-89.

[28] Abu-Jdayil, B., Al-Majeed Ghzawi, A., Al-Malah, K. I. M., and Zaitoun, S. 2002. "Heat Effect on Rheology of Light- and Dark-colored Honey." J. Food Eng. 51: 33-8.

[29] Israili, Z. H. 2014. “Antimicrobial Properties of Honey." Am. J. Therapeutics 21: 304-23.

[30] Kassim, M., Achoui, M., Mustafa, M. R., Mohd, M. A., and Yusoff, K. M. 2010. "Ellagic Acid, Phenolic Acids, and Flavonoids in Malaysian Honey Extracts Demonstrate in vitro Antiinflammatory Activity." Nutr. Res. 30: 650-9.

[31] Beretta, G., Granata, P., Ferrero, M., Orioli, M., and Maffei Facino, R. 2005. "Standardization of Antioxidant Properties of Honey by a Combination of Spectrophotometric/Fluorimetric Assays and Chemometrics." Anal. Chim. Acta 533: 185-91.

[32] Gheldof, N., Wang, X.-H., and Engeseth, N. J. 2002. "Identification and Quantification of Antioxidant Components of Honeys from Various Floral Sources." $J$. Agr. Food Chem. 50: 5870-7.

[33] Estevinho, L., Pereira, A. P., Moreira, L., Dias, L. G., and Pereira, E. 2008. "Antioxidant and Antimicrobial Effects of Phenolic Compounds Extracts of Northeast Portugal Honey." Food Chem. Toxicol. 46: 3774-9.

[34] Dias, L. G., Veloso, A. C., Sousa, M. E., Estevinho, L., Machado, A. A., and Peres, A. M. 2015. "A Novel Approach for Honey Pollen Profile Assessment Using an Electronic Tongue and Chemometric Tools." Anal. Chim. Acta 900: 36-45.

[35] Bobiş, O., Dezmirean, D. S., and Moise, A.R. 2018. "Honey and Diabets: The Importance of Natural Simple Sugars in Diet for Preventing and Treating Different Type of Diabets." Hindawi, Oxid. Med. Cell Longev. https://doi.org/10.1155/2018/4757893.

[36] Wilczyńska, A. 2014. "Effect of Filtration on Colour, Antioxidant Activity and Total Phenolics of Honey." LWT-Food Sci. Technol. 57: 767-74.

[37] Qiu, P., Ding, H., Tang, Y., and Xu, R. 1999. "Determination of Chemical Composition of Commercial Honey by Near-Infrared Spectroscopy." J. Agr. Food Chem. 47: 2760-5.

[38] Čanadanović-Brunet, J., Ćetković, G., Šaponjac, V. T., Stajčić, S., Vulić, J., Djilas, S., Štajner, D., and Popović, B. 2014. "Evaluation of Phenolic Content, Antioxidant Activity and Sensory Characteristics of Serbian Honey-based Product." Ind. Crops Prod. 62: 1-7. [39] Nagai, T., Inoue, R., Kanamori, N., Suzuki, N., and Nagashima, T. 2006. "Characterization of Honey from Different Floral Sources. Its Functional Properties and Effects of Honey Species on Storage of Meat." Food Chem. 97: 256-62. 